\title{
Glycemic Control in the Intensive Care Unit: A control systems perspective
}

\author{
J. Geoffrey Chase ${ }^{1}$, Balazs Benyo ${ }^{2}$ and Thomas Desaive ${ }^{3}$
}

1. Mechanical Engineering, Centre of Bio-Engineering, University of Canterbury, Christchurch, NZ; Geoff.chase@canterbury.ac.nz

2. Department of Control Engineering and Information Technology, Budapest University of Technology and Economics, Budapest, Hungary; bbenyo@iit.bme.hu

3. GIGA In Silico Medicine, Liege University, Liege, Belgium; tdesaive@uliege.be

\begin{abstract}
:
Computers and automation have revolutionised quality and productivity in many industries, but not in medicine. Healthcare costs are thus growing beyond the ability of society to pay for them, multiplied by the impact of increasingly aging populations, and specifically in the demand placed on intensive care unit (ICU) services. Glycemic control is a core ICU therapy with the potential to reduce both mortality and cost, which makes it an area where greater personalisation and automation could play a leading role in improving productivity and care. This review presents the background to the problem and the main issues arising in this area of care from a control systems technology perspective. It then presents a vision of a more automated future with specific goals in the areas of dynamic systems modeling, system identification and control. These areas are then given a state of the art review, mixing both medicine and control systems perspectives. It is concluded by specific recommendations for the field, where control systems expertise can be leveraged to best advantage.
\end{abstract}

Keywords: Glycemic Control, Control Systems, Dynamic Systems Modeling, System Identification, Identifiability, Intensive Care, ICU, Critical Care. 


\subsection{Introduction:}

Intensive care unit (ICU) patients are very difficult to manage safely and effectively as a result of their complex, nonlinear, and highly variable physiology and equally complex response to therapy. The cost of intensive care has risen dramatically in the last decade, primarily due to aging demographics and increasing average lifespans (e.g. [1, 2]), reducing the ability of health care systems to maintain equity of access to care, which is an increasingly important social and policy issue [3-8]. Thus, improving productivity and cost are the major current challenges for ICU care, where the personalisation and/or automation of care to better capture the intra- and inter- patient variability in core ICU therapies offers an opportunity to make a significant impact. In particular, changing from current "one size fits all" protocolised care, which can be problematic in the ICU [9-11], to a "one method fits all" personalised care, based on physiological models enabling optimised and automated therapy, could provide a means to address rising demand and costs.

High blood glucose (BG) or hyperglycemia is prevalent in critical care, and is one example area where such changes in care could have great impact. It is caused by a complex interaction of multiple feedback loops associated with inflammation resulting from immune responses, counter-regulatory responses, and high BG itself [12-15], and is thus a classic control systems problem in multiple variables. It is exacerbated by unsuppressed glucose production by the body [12-15], medications [16], high levels of naso-gastric nutrition [17], suppression of the body's insulin secretion [12-15], and loss of sensitivity to insulin $[18,19]$. All these factors effectively damage the body's normal feedback control mechanisms, resulting in reduced insulin-mediated glucose uptake, and thus hyperglycemia - in short the feedback loop is broken and control is extremely sub-optimal. Thus, there is a need for some form of supplemental, closed-loop, highly personalized glycemic control (GC) in critical care.

Hence, there are strong associations between BG level and/or variability with patient death [20-27]. However, poor control leading to low BG or hypoglycemia is also linked with increased mortality [25, 28-30], indicating the difficulty of the control problem in regulating BG to a band. These issues clearly state any control, automated or manual, must be achieved safely, despite the high inter- and intrapatient variability in response to care $[18,19,24,27,31-33]$, which can define these patients. 
Equally, and in contrast, safe, effective control has shown equivalent association of high times in intermediate BG bands with reduced mortality [34-39]. Thus, control quality must be consistent over time and most (or all) patients. However, relatively few studies achieved this level of consistent control [40-43], further demonstrating the problem difficulty and potential need for automation.

Thus, patient outcomes are driven by the quality and consistency of GC, as further demonstrated in recent analyses showing those patients who live and those who die are equally easy, or difficult, to control [44] - a control systems analysis of a clinical problem. However, GC in the ICU is still a controversial subject [45-51]. Some studies improved mortality with GC to a tight or intermediate range [40-43, 52], but several studies could not repeat these results [53-63]. The salient differences between these studies is based around the inability to directly manage inter- and intra- patient variability, yielding variable control quality for a given patient, inconsistency of control across patients, and thus a failure to deliver safe, effective control to all patients.

Overall, this analysis indicates the need for consistent, safe, effective control, which human driven or human in the loop driven protocols are unable to deliver. This need is reinforced by data from the single study that reduced mortality and hypoglycemia with GC [40]. This study also reduced organ failure, the leading cause of cost and mortality in ICU patients, and demonstrated that GC affects outcome for only an unidentifiable $15-20 \%$ of patients, which in turn reinforces the need to obtain safe, effective control for all patients [64], thus demanding a more rigorous control systems approach over clinical protocols.

This review discusses how physiological modelling of the complex, nonlinear metabolic system of the ICU patient can provide a means of identifying patient state, using that state to personalise care and manage intra- and inter- patient variability, and thus providing safe, effective and generalizable GC to all patients. A particular focus is put on how these elements can lead towards automated or semiautomated GC solutions, which would offer the opportunity to reduce nursing and doctor workload, while improving care, thus providing a context for merging physiology, health care, and control systems. 


\subsection{Vision of the Future:}

The problem can be summarised as the need to provide safe, generalizable, and effective GC to a diverse group of highly variable patients, in the presence of limited data. More specifically, it is possible to know the metabolic inputs of exogenous insulin and nutrition given to support the patient, but only the BG level is measured. In particular, this BG measurement can be intermittent in 1-4 hourly intervals, but with low error [65-69], or effectively continuous at intervals of 1-5 minutes using continuous glucose monitors (CGMs), but with increased error and drift [70-76]. Hence, automation must account for either intermittent control with high quality measurements of patient response, or more continuous feedback control with lower quality measurements, both of which will impact the shape and structure of control.

In all cases, the use of computational modelling offers the ability to turn these glucose measurements and known inputs into a better metric by which to guide care. In metabolic systems and GC, modelbased assessment of insulin sensitivity (SI) relates input changes of insulin and nutrition, to expected glycemic response. This value could be monitored and thus potentially used as a broader metric of patient condition. Finally, in an ideal case, model-based control using a metric of insulin sensitivity could be used not only to guide care, but to assess risk in terms of patient variability, thus offering the potential to manage patient variability directly in a risk-based approach to care.

Overall, models thus offer the ability to computationally derive a metric to guide control based on patient condition. They thus offer the potential to personalise that care, and to manage it based not only on condition, but on risk of variability, which would be unique in medicine today. This approach would be applicable to both direct closed-loop control, as well as semi-closed human in the loop control. This vision is illustrated schematically in Figure 1. 


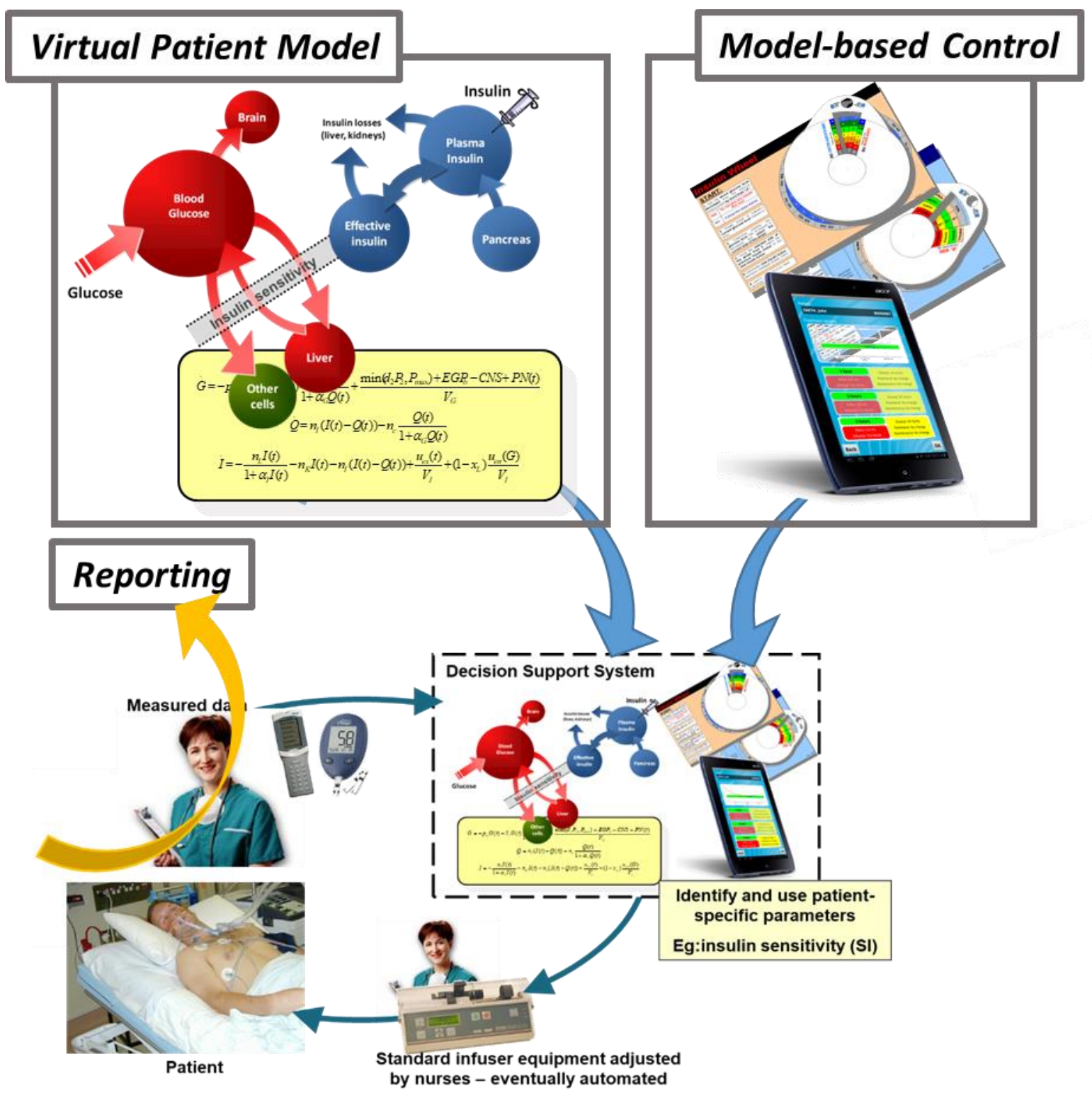

Figure 1: Model-based decision support to mimic the human pancreas with a nurse in the loop, but eventually automated. Measurements and other data are given to a decision support system that identifies patient-specific information, such as insulin sensitivity, to personalise the model. A control protocol uses that data to generate personalised recommendations for patient care 


\subsection{State of the Art:}

Computers and automation have revolutionised quality and productivity in many industries, but not in medicine $[7,77,78]$. Equally, and as noted, countries and health care systems are increasingly unable to pay for increasing demand and costs of medical care [79]. Computational physiological models and model-based control thus offer an important opportunity to personalise care, and improve costs and productivity, by combining clinical data with system identification methods to generate "virtual patient" [80-87] models to represent patients directly, the first step towards automating care.

In particular, there is, in general, an increasing range of physiological models, methods and databases, from simple to high complexity multi-scale models (e.g. [88-120]). Other reviews have delineated how each type of model might be used to guide care [83]. Validated models paired with appropriate control methods thus offer an avenue to translate computation into health care. The following sections outline the state of this art, specifically in relation to metabolic systems and glycemic control in the ICU.

\subsection{Dynamic System Models of the Metabolic System:}

There are several metabolic models of human metabolism particularly related to studies in diabetes and general physiology [82, 91, 96, 121-126]. They are primarily deterministic compartment models with specific terms for all relevant physiology and dynamics [91]. There are also black-box or data driven models with no direct physiological analogy or relevance (e.g. [127-134]). However, these black-box models do not offer the ability to generate patient-specific metabolic markers or accurate predictions of resulting glucose levels for an intervention of insulin or nutrition, which are necessary for model-based control and personalized GC to run in real-time with safety and efficacy.

Hence, this review focuses on less-complex models, where the minimum fundamental model inputs to simulate and/or personalize these models are the insulin and nutrition given, and blood glucose measurements. They thus offer the ability to be personalized to patient condition at a given BG measurement, and in turn used to predict the outcome to a next intervention. However, no discussion of possible models is complete due to the large number of models studied, so this review focuses on 
nonlinear metabolic system models used in critical care to create virtual patients, and use them to guide care, a much more limited set. Specifically:

- ICU Minimal Model [135, 136]

- Glucosafe [110]

- Cambridge [85]

- ICING [137-139]

- UVA/Padova [84, 140]

The ICU Minimal Model is based on the Bergman Minimal Model [113, 121], and is integral to the LOGIC controller [141]. It is the least physiologically relevant, with a minimal number of terms aggregating all glucose appearance and disappearance routes. An insulin sensitivity parameter derived from two model parameters makes it patient-specific and is used to guide care. It has been tested and improved control over nurse led GC [142], but was over aggressive in some cases. It is not currently a standard of care nor adopted for regular use.

Glucosafe is a dynamic model in its insulin kinetics, which are derived from an earlier form of the ICING model. However, its pharmacodynamics are based on a glucose-insulin dynamic model for diabetes control [143]. Insulin sensitivity is identified from data and has been used to create virtual patients to develop glycemic controllers [110]. It is more physiologically relevant than the ICU Minimal Model with specific pharmacodynamics terms for each form of glucose removal. However, it demonstrated limited performance in pilot GC trials in regular and neuro ICU patients [31, 144].

The Cambridge Model is highly physiologically relevant [85]. It was developed from frequently sampled bedside data collected at the ICU and underlying models developed for physiology and diabetes experiments and control $[99,145-147]$. It has been used to simulate and design GC in critical care, specifically in creating multi-day clones $[85,119,148]$ of critical care patients. It uses identified timevarying insulin sensitivity $(\mathrm{SI})$ to guide care and mitigate errors in combination with a black-box autoregressive model [146]. 
The ICING model also has high physiological relevance with specific pathways modeled for the main forms of glucose appearance and uptake [137, 139]. It also has a neonatal ICU (NICU) version based on the same dynamics scaled for the specific case $[87,138,149]$. It is driven by an insulin sensitivity parameter identifiable from bedside data $[150,151]$, which can be used to monitor patient condition and its evolution over time $[18,152,153]$. It has been used in virtual patients $[139,154,155]$, GC design [155-157] and real-time GC [155-159]. In particular, it has been used to create multi-day virtual patient clones, where predicted cohort level glycemic results were matched by subsequent clinical results (e.g. $[80,156])$ with good correlation of median per-patient glucose levels. It has also demonstrated crossvalidation of its virtual patients on independent data on multiple data sets $[139,154]$, and is thus the most completely validated model based on a recent framework [83]. All these results indicate that its monitoring of patient condition accurately captures the necessary dynamics.

The UVA/Padova simulator was developed for type 1 diabetes [84, 140], and is a collection of highly physiologically relevant sub-models, rather than a single mode. Its high physiological relevance and detail are an advantage in physiological studies. It has been used for single day virtual patient clones [160]. However, a given insulin sensitivity or other key parameters cannot necessarily be identified from bedside data with this model, and it has multiple insulin sensitivities. It is thus limited it to simulations of generic patients, and while it is not yet validated for direct clinical use in model-based control, it has been approved by the US FDA for replacing the need for some clinical trials [84].

While this brief overview is not exhaustive, it clearly highlights the need for "valid models" meeting three main criteria. First, an identifiable insulin sensitivity parameter capturing patient-specific glucose responses to insulin-nutrition inputs to enable personalisation. Second, a large enough degree of physiological relevance to ensure identified parameter(s) accurately capture patient-specific behavior so they can be used to design and/or guide care. Third, rigorous validation via use in design and/or implementation of safe, effective GC. These issues are inter-related, and thus reviewed in subsequent sections in terms of the use of these models as Virtual Patients to design and guide care, and their subsequent use in guiding GC. 
Overall, 4 of the 5 models have been used to both design GC, as well as implement it. However, only the Cambridge and ICING models have had outcome success clinically, where the ICING model modified for the NICU (called the NICING model) has been generalized to other critical care cases clinically $[138,158]$. This difference may be due to the fact that, to date, only these 2 models have been validated using independent cohorts and protocols $[139,148,154]$.

Equally, both models use a model-identified insulin sensitivity parameter $(\mathrm{SI})$ which has been proven in independent insulin sensitivity studies [152, 161-164]. This metric is critical as it is used to guide care, and inaccuracy will translate through to any control derived using its value with potential patient harm. Perhaps more importantly, such model-based SI [19, 33, 85, 109, 110, 114, 117, 137, 154, 161, 165173] can be monitored and its level and/or variation assessed relative to condition $[16,18,19,153,171$, 174-182]. Thus, if accurate, this value offers not only the potential of good, personalised control, but also further insight into patient condition.

Overall, the current state of the art in terms of metabolic models for this application is limited. In particular, model-based control in other industries may have several models to choose from. However, these models have performed well. Still, further research may be required and there is no "best" control relevant dynamic system model of human metabolism, for the critically ill or in diabetes, at this time.

\subsection{Model Validation:}

Model validation is a difficult topic, although clinical application, as discussed in Section 3.1, provides a final proof if the resulting control is good. Many models in physiology focus on the ability to fit the data, meeting the simplest standard. However, such limited validation does not ensure the dynamics modelled are those produced by the actual system. In particular, a model may fit measured data using the as-identified parameters, but while the fit is good, the identified model cannot accurately predict forward when conditions or inputs change. As a result, the identified cannot be said to accurately represent the same dynamics as those observed in the patient when conditions change. Thus, prediction of outcome has emerged as the necessary minimum in physiological modelling for control or decision support, where the identified model needs to be able to predict the outcome of an intervention and thus demonstrate its potential for safe, effective control, which is the end goal in this case. 
A recent review [83] thus developed a framework for validation, beginning at prediction. It also proposed validation in predicting the outcome of groups of experiments or clinical interventions over cohorts, expanding from single virtual patient predictions using an identified model, to prediction accuracy across groups of patients, an added level of robustness. Finally, it proposed cohort level cross-validation using independent clinical data to identify similar cohorts and test their prediction on the protocols or interventions applied to the other cohort, the highest level of validation. To date, as noted previously, only the ICING and Cambridge models offer the first two levels of validation, and only the ICING model the third level.

\subsection{Closed Loop and Decision Support to Guide Care:}

Figure 1 schematically shows the use of these models as part of either partial or full closed loop automation. As noted, both the Cambridge and ICING models have been used in clinical GC, and have been used as standard of care in multiple ICUs. Notably, and as illustrated, the field has devolved in model predictive forms of control, using glucose measurements for closed loop control of BG levels. More specifically, predictive control requires a model using current measurements and other inputs to identify patient-specific model parameters to personalize GC. The patient-specific model is then used to predict the outcome of insulin-nutrition interventions to optimize glycemic performance. Thus, the model is used directly in the control loop.

Although several model-based predictive controllers have been tested in short or limited trials, only a few have been used regularly in major trials $[141,142]$ or as standard of care $[159,171]$. There are two essential control approaches taken to date:

- Target to value (TTV), where GC is optimized to achieve a specified BG target value;

- Target to range or risk (TTR), where GC is optimized using models of metabolic variability to provide a specified risk of hypo- and/or hyper- glycemia.

The LOGIC-Insulin system is a TTV approach and nutrition is clinically set and not controlled, and thus it does not use one potential control input in achieving desired BG levels. The single-center LOGIC-I 
trial [141] compared standard care at a unit with a very strong reputation for nursing-led GC to modelbased care with very good results. This performance was confirmed in a smaller multicenter trial [142]. However, it is not yet a standard of care yet in the original study unit or elsewhere.

The TTV eMPC (B. Braun, Germany) [146] is based on the Cambridge model, and has been used several trials [171, 183-186]. It also controls only insulin infusions, leaving nutrition as clinically set, and thus also does not use one potential control input in achieving desired BG levels. Compared to standard care, eMPC does well $[183,186]$. Comparisons across centers and cohorts show similar, but not identical, performance $[171,185]$. Workload is $14-18$ measurements/day, and thus higher than standard care in most ICUs. Thus, eMPC provides improved care and safety, but increases potential workload. It is used regularly in some ICUs. More recently, the Cambridge model and similar controller has been used in guiding infusions in type 2 diabetes patients in the ICU and less acute wards [187].

STAR is the only TTR system and controls both insulin and nutrition inputs [188, 189], thus using both possible control inputs. It uses a unique risk-based stochastic forecasting [71] based on unique and increasingly complex stochastic models of future insulin sensitivity variability over 1-4 hours ahead [166, $167,176,177,190,191]$. The approach is used in both the ICU $[156,159]$ and NICU $[87,138,158$, 170], where notably insulin is the only control variable in the NICU for clinical reasons. STAR is thus the only GC system to directly account for future variability and to directly manage it in the control scheme. Within the control systems engineering field, there are potentially other methods of approaching this capability, such as a range of auto-regressive models, which again could be built from increasing clinical data in use.

STAR also has good performance and safety, including high times in intermediate glycemic bands, approaching $80 \%$ with 10-13 measurements/day [156, 159], and similar results in NICU [158, 192]. More importantly, it has very low rates of hypoglycemia, which is especially important in the NICU case where GC leads to excessive hypoglycemia in other clinical studies $[193,194]$. STAR in the adult ICU has generalized well, with almost identical glycemic outcomes across very different cohorts and ICUs [159]. Notably, eMPC and LOGIC-Insulin have shown some generalizability, but not to the near identical level across very different cohorts. 
An important difference for STAR over the other two controllers is its use of nutrition in control. Increased insulin and reduced nutrition are two control inputs available to reduce BG levels. In a control systems context, particularly given the risk of hypoglycemia with excessive insulin, it is sensible to control both inputs, and there is no major clinical difficulty in doing so, particularly with automation. However, it is not typical clinical practice, and there is fear of underfeeding patients [195-198]. However, in separate analyses STAR was shown to provide nutrition near to best in the world compared to a large survey of international ICUs [199], and further analysis has shown the potential to control nutrition at a range of time resolutions or servo-rates to overcome clinical hesitancy though they have not yet been tested [200].

All three model-based systems noted have very low rates of hypoglycaemia $(<5 \%$ by patient) and are very generalizable. Note, the Glucosafe system was not included as it has only been used for trials of 10-20 patients and thus not demonstrated the same robustness in care as the other three, and that only two of those three models are used in standard of care over time. Overall, this analysis shows predictive, model-based methods can overcome many of the hurdles that have hindered clinical trials in the field.

In summary, at this time, in addition to very simple, model-free PID (Proportional-Integra-Derivative) feedback control systems used in some hospitals in the US [201-203], three model-based predictive GC methods have proved reliable over multiple patient types and centers. Two are used as standards of care in multiple hospitals, and one has a NICU version [138] as standard of care, which is currently being used in a wider randomized trial [204]. Two methods consider nutrition (STAR, eMPC), although only one (STAR) controls it, which may account for some differences in performance and generalizability across diverse cohorts with different levels of insulin sensitivity [205].

\subsection{Summary and Future Possibilities:}

This section presented an overview of the metabolic models available for GC in the ICU, and how they can be, or have been, used in clinical care. To date, there are limited models and most are limited in the scale, number, and level of validation. There is thus significant research opportunity for new developments, including in the inclusion or clinical use of device dynamics, where, for example, insulin 
adsorption to infusion lines [206, 207] and infusion pump dynamics $[208,209]$ are not accounted for as yet, but may play a major role. Equally, the use of continuous glucose monitors (CGMs) for far higher bandwidth control has been only little studied in this context (e.g. $[73,210])$, and there is a dearth of CGM dynamics models to help design and guide control, where their drift and error could significantly impact control quality. 


\subsection{Recommendations:}

From the analysis and review there are significant areas in which the control of blood glucose in hospital, and with outpatients (not covered here) cross over into the realms typically covered by control systems engineers. As devices and systems provide the ability for greater real-time measurement and control, these inputs will become increasingly relevant. Thus, the following recommendations might be made relevant to the control systems field as a whole:

- There is a growing need for far better methods of dynamic systems modelling in this area, with a particular focus on accurate, nonlinear models, which capture more relevant dynamics based either on existing data or data taken during care. In particular, better modelling of insulin kinetics, glucose appearance from the gut, and endogenous glucose production, all of which are highly variable in critical illness and difficult to measure directly would significantly improve model-based control accuracy. However, these models must also be simultaneously identifiable from the data available, which could be used to efficiently implement personalised, model predictive forms of control. Thus, model creation, analysis, and identifiability, all of which are core areas of control systems engineering, are an increasing need in this field to advance the models and methods, as the potential of real-time control emerges in the area.

- There is a growing need to better process those measurements available, such as those from continuous glucose monitors, where, in particular, the identification of sensor drift or unusual measurements indicating sensor fault would dramatically enhance control capability. Again, these points cross into traditional and current areas of control systems engineering.

- Finally, there is a major need for better, and computationally faster optimisation methods for parameter identification, both deterministic, direct approaches, as well as approaches including or solely using machine learning and bigger data sets. Better, faster identification of more parameters to maximise the data available will enable better, more accurate control, and is a direct application of control systems engineering to this biomedical problem. 
All three points above are noted to first show the crossover of these areas with traditional control systems theory and methods, as well as to drive home the key areas where current methods are lacking, and new approaches could have significant impact on the field, as well as on patients. 


\subsection{Conclusions:}

The systematic review presented has addressed model-based, personalised glycemic control. It has presented the problem and the current state of the art. There has been an ongoing focus to relate the ideas and current state back to traditional control systems methods and engineering approaches. The review shows that while the field itself is vibrant, the results to date are narrow and there is significant room for innovation and new approaches, particularly as more and more data becomes available to engineers, and clinicians become increasingly willing to take on more novel approaches driven by rapid changes in technology and the ability to measure and control patients. These changes will only occur more rapidly as both technology and economics drives a need for both better patient care and outcomes, as well as a need for greater productivity so the care remains affordable for patients and payers. There is thus significant impetus to see control systems and automation in this area, as well as other areas of medicine, and a range of technologies increasingly capable of enabling next-generation, personalised, predictive, and productive forms of care. 


\subsection{References:}

1. Halpern, N.A., Can the costs of critical care be controlled? Curr Opin Crit Care, 2009. 15(6): p. 591-6.

2. Shorr, A.F., An update on cost-effectiveness analysis in critical care. Curr Opin Crit Care, 2002. 8(4): p. 337-43.

3. Halpern, S.D., ICU capacity strain and the quality and allocation of critical care. Curr Opin Crit Care, 2011. 17(6): p. 648-57.

4. van Exel, J., R. Baker, H. Mason, C. Donaldson, W. Brouwer, and Q.T. EuroVa, Public views on principles for health care priority setting: findings of a European cross-country study using $Q$ methodology. Soc Sci Med, 2015. 126: p. 128-37.

5. Orsini, J., C. Blaak, A. Yeh, X. Fonseca, T. Helm, A. Butala, and J. Morante, Triage of Patients Consulted for ICU Admission During Times of ICU-Bed Shortage. J Clin Med Res, 2014. 6(6): p. 463-8.

6. Truog, R.D., D.W. Brock, D.J. Cook, M. Danis, J.M. Luce, G.D. Rubenfeld, M.M. Levy, E. Task Force on Values, and C. Rationing in Critical, Rationing in the intensive care unit. Crit Care Med, 2006. 34(4): p. 958-63; quiz 971.

7. Baumol, W.J. and D.M. De Ferranti, The cost disease : why computers get cheaper and health care doesn't. 2012, New Haven: Yale University Press. xxi, 249 p.

8. Dombovy, M.L., U.S. health care in conflict--Part I. The challenges of balancing cost, quality and access. Physician Exec, 2002. 28(4): p. 43-7.

9. Amerling, R., J.F. Winchester, and C. Ronco, Guidelines have done more harm than good. Blood Purif, 2008. 26(1): p. 73-6.

10. Fernandez, A., J. Sturmberg, S. Lukersmith, R. Madden, G. Torkfar, R. Colagiuri, and L. Salvador-Carulla, Evidence-based medicine: is it a bridge too far? Health Res Policy Syst, 2015. 13: p. 66.

11. Naylor, A.R., Interventions for carotid artery disease: time to confront some 'inconvenient truths'. Expert Rev Cardiovasc Ther, 2007. 5(6): p. 1053-63.

12. Dungan, K.M., S.S. Braithwaite, and J.C. Preiser, Stress hyperglycaemia. Lancet, 2009. 373(9677): p. 1798-807.

13. Marik, P.E. and M. Raghavan, Stress-hyperglycemia, insulin and immunomodulation in sepsis. Intensive Care Medicine, 2004. 30(5): p. 748-756.

14. Marik, P.E. and R. Bellomo, Stress hyperglycemia: an essential survival response! Crit Care, 2013. 17(2): p. 305.

15. McCowen, K.C., A. Malhotra, and B.R. Bistrian, Stress-induced hyperglycemia. Crit Care Clin, 2001. 17(1): p. 107-124.

16. Pretty, C., J.G. Chase, J. Lin, G.M. Shaw, A. Le Compte, N. Razak, and J.D. Parente, Impact of glucocorticoids on insulin resistance in the critically ill. Comput Methods Programs Biomed, 2011. 102(2): p. 172-80.

17. Rice, T.W., Gluttony in the intensive care unit: time to push back from the consensus table. Am J Respir Crit Care Med, 2013. 187(3): p. 223-4.

18. Pretty, C.G., A.J. Le Compte, J.G. Chase, G.M. Shaw, J.C. Preiser, S. Penning, and T. Desaive, Variability of insulin sensitivity during the first 4 days of critical illness: implications for tight glycemic control. Ann Intensive Care, 2012. 2(1): p. 17.

19. Langouche, L., S. Vander Perre, P.J. Wouters, A. D'Hoore, T.K. Hansen, and G. Van den Berghe, Effect of intensive insulin therapy on insulin sensitivity in the critically ill. J Clin Endocrinol Metab, 2007. 92(10): p. 3890-7.

20. Ali, N.A., J.M. O'Brien, Jr., K. Dungan, G. Phillips, C.B. Marsh, S. Lemeshow, A.F. Connors, Jr., and J.C. Preiser, Glucose variability and mortality in patients with sepsis. Crit Care Med, 2008. 36(8): p. 2316-21.

21. Egi, M., R. Bellomo, E. Stachowski, C.J. French, and G. Hart, Variability of blood glucose concentration and short-term mortality in critically ill patients. Anesthesiology, 2006. 105(2): p. 244-52.

22. Egi, M., S. Finfer, and R. Bellomo, Glycemic control in the ICU. Chest, 2011. 140(1): p. 212-20.

23. Krinsley, J.S., Glycemic variability: a strong independent predictor of mortality in critically ill patients. Crit Care Med, 2008. 36(11): p. 3008-13.

24. Waeschle, R.M., O. Moerer, R. Hilgers, P. Herrmann, P. Neumann, and M. Quintel, The impact of the severity of sepsis on the risk of hypoglycaemia and glycaemic variability. Critical care (London, England), 2008. 12(5): p. R129. 
25. Bagshaw, S.M., R. Bellomo, M.J. Jacka, M. Egi, G.K. Hart, C. George, and A.C.M. Committee, The impact of early hypoglycemia and blood glucose variability on outcome in critical illness. Crit Care, 2009. 13(3): p. R91.

26. Donati, A., E. Damiani, R. Domizi, L. Botticelli, R. Castagnani, V. Gabbanelli, S. Nataloni, A. Carsetti, C. Scorcella, E. Adrario, P. Pelaia, and J.C. Preiser, Glycaemic variability, infections and mortality in a medical-surgical intensive care unit. Crit Care Resusc, 2014. 16(1): p. 13-23.

27. Kauffmann, R.M., R.M. Hayes, B.D. Buske, P.R. Norris, T.R. Campion, Jr., M. Dortch, J.M. Jenkins, B.R. Collier, and A.K. May, Increasing blood glucose variability heralds hypoglycemia in the critically ill. J Surg Res, 2011. 170(2): p. 257-64.

28. Krinsley, J.S., M.J. Schultz, P.E. Spronk, R.E. Harmsen, F. van Braam Houckgeest, J.P. van der Sluijs, C. Melot, and J.C. Preiser, Mild hypoglycemia is independently associated with increased mortality in the critically ill. Crit Care, 2011. 15(4): p. R173.

29. Investigators, N.-S.S., S. Finfer, B. Liu, D.R. Chittock, R. Norton, J.A. Myburgh, C. McArthur, I. Mitchell, D. Foster, V. Dhingra, W.R. Henderson, J.J. Ronco, R. Bellomo, D. Cook, E. McDonald, P. Dodek, P.C. Hebert, D.K. Heyland, and B.G. Robinson, Hypoglycemia and risk of death in critically ill patients. N Engl J Med, 2012. 367(12): p. 1108-18.

30. Egi, M., R. Bellomo, E. Stachowski, C.J. French, G.K. Hart, G. Taori, C. Hegarty, and M. Bailey, Hypoglycemia and outcome in critically ill patients. Mayo Clin Proc, 2010. 85(3): p. 217-24.

31. Pielmeier, U., M.L. Rousing, S. Andreassen, B.S. Nielsen, and P. Haure, Decision support for optimized blood glucose control and nutrition in a neurotrauma intensive care unit: preliminary results of clinical advice and prediction accuracy of the Glucosafe system. J Clin Monit Comput, 2012. 26(4): p. 319-28.

32. Krinsley, J.S., D.E. Bruns, and J.C. Boyd, The impact of measurement frequency on the domains of glycemic control in the critically ill--a Monte Carlo simulation. J Diabetes Sci Technol, 2015. 9(2): p. 237-45.

33. Chase, J.G., A.J. Le Compte, F. Suhaimi, G.M. Shaw, A. Lynn, J. Lin, C.G. Pretty, N. Razak, J.D. Parente, and C.E. Hann, Tight glycemic control in critical care-The leading role of insulin sensitivity and patient variability: A review and model-based analysis. Computer Methods and Programs in Biomedicine, 2011. 102(2): p. 156-171.

34. Al-Tarifi, A., N. Abou-Shala, H.M. Tamim, A.H. Rishu, and Y.M. Arabi, What is the optimal blood glucose target in critically ill patients? A nested cohort study. Ann Thorac Med, 2011. 6(4): p. 207-11.

35. Omar, A.S., A. Salama, M. Allam, Y. Elgohary, S. Mohammed, A.K. Tuli, and R. Singh, Association of time in blood glucose range with outcomes following cardiac surgery. BMC Anesthesiol, 2015. 15: p. 14.

36. Krinsley, J.S. and J.C. Preiser, Time in blood glucose range 70 to $140 \mathrm{mg} / \mathrm{dl}>80 \%$ is strongly associated with increased survival in non-diabetic critically ill adults. Crit Care, 2015. 19: p. 179.

37. Signal, M., A. Le Compte, G.M. Shaw, and J.G. Chase, Glycemic levels in critically ill patients: are normoglycemia and low variability associated with improved outcomes? J Diabetes Sci Technol, 2012. 6(5): p. 1030-7.

38. Penning, S., J.G. Chase, J.C. Preiser, C.G. Pretty, M. Signal, C. Melot, and T. Desaive, Does the achievement of an intermediate glycemic target reduce organ failure and mortality? A post hoc analysis of the Glucontrol trial. J Crit Care, 2014. 29(3): p. 374-9.

39. Penning, S., C. Pretty, J.C. Preiser, G.M. Shaw, T. Desaive, and J.G. Chase, Glucose control positively influences patient outcome: A retrospective study. J Crit Care, 2015. 30(3): p. 455-9.

40. Chase, J.G., G. Shaw, A. Le Compte, T. Lonergan, M. Willacy, X.W. Wong, J. Lin, T. Lotz, D. Lee, and C. Hann, Implementation and evaluation of the SPRINT protocol for tight glycaemic control in critically ill patients: a clinical practice change. Crit Care, 2008. 12(2): p. R49.

41. Krinsley, J.S., Effect of an intensive glucose management protocol on the mortality of critically ill adult patients. Mayo Clin Proc, 2004. 79(8): p. 992-1000.

42. Van den Berghe, G., P. Wouters, F. Weekers, C. Verwaest, F. Bruyninckx, M. Schetz, D. Vlasselaers, P. Ferdinande, P. Lauwers, and R. Bouillon, Intensive insulin therapy in the critically ill patients. N Engl J Med, 2001. 345(19): p. 1359-1367.

43. Van den Berghe, G., A. Wilmer, G. Hermans, W. Meersseman, P.J. Wouters, I. Milants, E. Van Wijngaerden, H. Bobbaers, and R. Bouillon, Intensive Insulin Therapy in the Medical ICU. N Engl J Med, 2006. 354(5): p. 449-61.

44. Uyttendaele, V., J.L. Dickson, G.M. Shaw, T. Desaive, and J.G. Chase, Untangling glycaemia and mortality in critical care. Crit Care, 2017. 21(1): p. 152.

45. Marik, P.E., Precision Glycemic Control in the ICU. Crit Care Med, 2016. 44(7): p. 1433-4. 
46. Schultz, M.J., R.E. Harmsen, and P.E. Spronk, Clinical review: Strict or loose glycemic control in critically ill patients--implementing best available evidence from randomized controlled trials. Crit Care, 2010. 14(3): p. 223.

47. Gunst, J. and G. Van den Berghe, Blood glucose control in the ICU: don't throw out the baby with the bathwater! Intensive Care Med, 2016. 42(9): p. 1478-81.

48. Preiser, J.C. and H.M. Straaten, Glycemic control: please agree to disagree. Intensive Care Med, 2016. 42(9): p. 1482-4.

49. Marik, P.E., Tight glycemic control in acutely ill patients: low evidence of benefit, high evidence of harm! Intensive Care Med, 2016. 42(9): p. 1475-7.

50. Polderman, K.H. and A.R. Girbes, Intensive insulin therapy: of harm and health, of hypes and hypoglycemia. Crit Care Med, 2006. 34(1): p. 246-8.

51. Brunkhorst, F.M. and K. Reinhart, Intensive insulin therapy in the ICU: benefit versus harm? Intensive Care Med, 2007. 33(7): p. 1302.

52. Reed, C.C., R.M. Stewart, M. Sherman, J.G. Myers, M.G. Corneille, N. Larson, S. Gerhardt, R. Beadle, C. Gamboa, D. Dent, S.M. Cohn, and B.A. Pruitt, Jr., Intensive insulin protocol improves glucose control and is associated with a reduction in intensive care unit mortality. J Am Coll Surg, 2007. 204(5): p. 1048-54; discussion 1054-5.

53. Finfer, S., D.R. Chittock, S.Y. Su, D. Blair, D. Foster, V. Dhingra, R. Bellomo, D. Cook, P. Dodek, W.R. Henderson, P.C. Hebert, S. Heritier, D.K. Heyland, C. McArthur, E. McDonald, I. Mitchell, J.A. Myburgh, R. Norton, J. Potter, B.G. Robinson, and J.J. Ronco, Intensive versus conventional glucose control in critically ill patients. N Engl J Med, 2009. 360(13): p. 1283-97.

54. Preiser, J.C., P. Devos, S. Ruiz-Santana, C. Melot, D. Annane, J. Groeneveld, G. lapichino, X. Leverve, G. Nitenberg, P. Singer, J. Wernerman, M. Joannidis, A. Stecher, and R. Chiolero, $A$ prospective randomised multi-centre controlled trial on tight glucose control by intensive insulin therapy in adult intensive care units: the Glucontrol study. Intensive Care Med, 2009. 35(10): p. 1738 - 1748.

55. Brunkhorst, F.M., C. Engel, F. Bloos, A. Meier-Hellmann, M. Ragaller, N. Weiler, O. Moerer, M. Gruendling, M. Oppert, S. Grond, D. Olthoff, U. Jaschinski, S. John, R. Rossaint, T. Welte, M. Schaefer, P. Kern, E. Kuhnt, M. Kiehntopf, C. Hartog, C. Natanson, M. Loeffler, K. Reinhart, and S. German Competence Network, Intensive insulin therapy and pentastarch resuscitation in severe sepsis. N Engl J Med, 2008. 358(2): p. 125-39.

56. Marik, P.E. and J.C. Preiser, Toward understanding tight glycemic control in the ICU: a systematic review and metaanalysis. Chest, 2010. 137(3): p. 544-51.

57. Fahy, B.G., A.M. Sheehy, and D.B. Coursin, Glucose control in the intensive care unit. Crit Care Med, 2009. 37(5): p. 1769-76.

58. Treggiari, M.M., V. Karir, N.D. Yanez, N.S. Weiss, S. Daniel, and S.A. Deem, Intensive insulin therapy and mortality in critically ill patients. Crit Care, 2008. 12(1): p. R29.

59. Arabi, Y.M., O.C. Dabbagh, H.M. Tamim, A.A. Al-Shimemeri, Z.A. Memish, S.H. Haddad, S.J. Syed, H.R. Giridhar, A.H. Rishu, M.O. Al-Daker, S.H. Kahoul, R.J. Britts, and M.H. Sakkijha, Intensive versus conventional insulin therapy: a randomized controlled trial in medical and surgical critically ill patients. Crit Care Med, 2008. 36(12): p. 3190-7.

60. De La Rosa, C., J.H. Donado, A.H. Restrepo, A.M. Quintero, L.G. Gonzalez, N.E. Saldarriaga, M. Bedoya, J.M. Toro, J.B. Velasquez, J.C. Valencia, C.M. Arango, P.H. Aleman, E.M. Vasquez, J.C. Chavarriaga, A. Yepes, W. Pulido, and C.A. Cadavid, Strict glycaemic control in patients hospitalised in a mixed medical and surgical intensive care unit: a randomised clinical trial. Crit Care, 2008. 12(5): p. R120.

61. Griesdale, D.E., R.J. de Souza, R.M. van Dam, D.K. Heyland, D.J. Cook, A. Malhotra, R. Dhaliwal, W.R. Henderson, D.R. Chittock, S. Finfer, and D. Talmor, Intensive insulin therapy and mortality among critically ill patients: a meta-analysis including NICE-SUGAR study data. CMAJ, 2009. 180(8): p. 821-827.

62. Wiener, R.S., D.C. Wiener, and R.J. Larson, Benefits and risks of tight glucose control in critically ill adults: a meta-analysis. JAMA, 2008. 300(8): p. 933-44.

63. Preiser, J.C., P. Devos, and R. Chiolero, Which factors influence glycemic control in the intensive care unit? Curr Opin Clin Nutr Metab Care, 2010. 13(2): p. 205-10.

64. Chase, J.G., C.G. Pretty, L. Pfeifer, G.M. Shaw, J.C. Preiser, A.J. Le Compte, J. Lin, D. Hewett, K.T. Moorhead, and T. Desaive, Organ failure and tight glycemic control in the SPRINT study. Crit Care, 2010. 14(4): p. R154.

65. Signal, M., L. Fisk, G.M. Shaw, and J.G. Chase, Concurrent continuous glucose monitoring in critically ill patients: interim results and observations. J Diabetes Sci Technol, 2013. 7(6): p. 1652-3. 
66. Devreese, K. and G. Leroux-Roels, Laboratory assessment of five glucose meters designed for self-monitoring of blood glucose concentration. Eur J Clin Chem Clin Biochem, 1993. 31(12): p. 829-37.

67. Pretty, C.G., M. Signal, L. Fisk, S. Penning, A. Le Compte, G.M. Shaw, T. Desaive, and J.G. Chase, Impact of sensor and measurement timing errors on model-based insulin sensitivity. Comput Methods Programs Biomed, 2014. 114(3): p. e79-86.

68. Solnica, B., J.W. Naskalski, and J. Sieradzki, The evaluation of analytical performance of the Precision G point-of-care glucometer. Clin Chem Lab Med, 2001. 39(12): p. 1283-6.

69. Solnica, B., J.W. Naskalski, and J. Sieradzki, Analytical performance of glucometers used for routine glucose self-monitoring of diabetic patients. Clin Chim Acta, 2003. 331(1-2): p. 29-35.

70. Biagi, L., C.M. Ramkissoon, A. Facchinetti, Y. Leal, and J. Vehi, Modeling the Error of the Medtronic Paradigm Veo Enlite Glucose Sensor. Sensors (Basel), 2017. 17(6).

71. Facchinetti, A., S. Del Favero, G. Sparacino, J.R. Castle, W.K. Ward, and C. Cobelli, Modeling the glucose sensor error. IEEE Trans Biomed Eng, 2014. 61(3): p. 620-9.

72. Reifman, J., S. Rajaraman, A. Gribok, and W.K. Ward, Predictive monitoring for improved management of glucose levels. J Diabetes Sci Technol, 2007. 1(4): p. 478-86.

73. Zhou, T., J.L. Dickson, G.M. Shaw, and J.G. Chase, Continuous Glucose Monitoring Measures Can Be Used for Glycemic Control in the ICU: An In-Silico Study. J Diabetes Sci Technol, 2018. 12(1): p. 7-19.

74. Zhou, T., J.L. Dickson, and J. Geoffrey Chase, Autoregressive Modeling of Drift and Random Error to Characterize a Continuous Intravascular Glucose Monitoring Sensor. J Diabetes Sci Technol, 2018. 12(1): p. 90-104.

75. Breton, M. and B. Kovatchev, Analysis, Modeling, and Simulation of the Accuracy of Continuous Glucose Sensors. J Diabetes Sci Technol, 2008. 2(5): p. 853-862.

76. Signal, M., R. Gottlieb, A. Le Compte, and J.G. Chase, Continuous glucose monitoring and trend accuracy: news about a trend compass. J Diabetes Sci Technol, 2014. 8(5): p. 986-97.

77. Economist, T., Patient, heal thyself, in The Economist 2011, The Economist: London, UK. p. 2.

78. Micklethwait, J., Taming Leviathan, in The Economist. 2011, The Economist: London, UK. p. 6.

79. OECD, FOCUS on Health Spending @ OECD Health Statistics 2015. OECD Health Statistics 2015, 2015. July 2015: p. 1-8.

80. Chase, J.G., G.M. Shaw, T. Lotz, A. LeCompte, J. Wong, J. Lin, T. Lonergan, M. Willacy, and C.E. Hann, Model-based insulin and nutrition administration for tight glycaemic control in critical care. Curr Drug Deliv, 2007. 4(4): p. 283-96.

81. Chase, J., T. Desaive, and J.C. Preiser, Virtual Patients and Virtual Cohorts: A New Way to Think About the Design and Implementation of Personalized ICU Treatments, in Annual Update in Intensive Care and Emergency Medicine, J.L. Vincent, Editor. 2016. p. 435-448.

82. Chase, J.G., T. Desaive, J. Bohe, M. Cnop, C. De Block, J. Gunst, R. Hovorka, P. Kalfon, J. Krinsley, E. Renard, and J.C. Preiser, Improving glycemic control in critically ill patients: personalized care to mimic the endocrine pancreas. Crit Care, 2018. 22(1): p. 182.

83. Chase, J.G., J.C. Preiser, J.L. Dickson, A. Pironet, Y.S. Chiew, C.G. Pretty, G.M. Shaw, B. Benyo, K. Moeller, S. Safaei, M. Tawhai, P. Hunter, and T. Desaive, Next-generation, personalised, model-based critical care medicine: a state-of-the art review of in silico virtual patient models, methods, and cohorts, and how to validation them. Biomed Eng Online, 2018. 17(1): p. 24.

84. Dalla Man, C., F. Micheletto, D. Lv, M. Breton, B. Kovatchev, and C. Cobelli, The UVA/PADOVA Type 1 Diabetes Simulator: New Features. J Diabetes Sci Technol, 2014. 8(1): p. 26-34.

85. Hovorka, R., L.J. Chassin, M. Ellmerer, J. Plank, and M.E. Wilinska, A simulation model of glucose regulation in the critically ill. Physiol Meas, 2008. 29(8): p. 959-78.

86. Kanderian, S.S., S.A. Weinzimer, and G.M. Steil, The identifiable virtual patient model: comparison of simulation and clinical closed-loop study results. J Diabetes Sci Technol, 2012. 6(2): p. 371-9.

87. Le Compte, A.J., J.G. Chase, A. Lynn, C.E. Hann, G.M. Shaw, and J. Lin, Development of blood glucose control for extremely premature infants. Comput Methods Programs Biomed, 2011. 102(2): p. 181-91.

88. Cooling, M.T. and P. Hunter, The CelIML Metadata Framework 2.0 Specification. J Integr Bioinform, 2015. 12(2): p. 260.

89. Nickerson, D.P., D. Ladd, J.R. Hussan, S. Safaei, V. Suresh, P.J. Hunter, and C.P. Bradley, Using CellML with OpenCMISS to Simulate Multi-Scale Physiology. Front Bioeng Biotechnol, 2014. 2: p. 79. 
90. Yu, T., C.M. Lloyd, D.P. Nickerson, M.T. Cooling, A.K. Miller, A. Garny, J.R. Terkildsen, J. Lawson, R.D. Britten, P.J. Hunter, and P.M. Nielsen, The Physiome Model Repository 2. Bioinformatics, 2011. 27(5): p. 743-4.

91. Carson, E.R. and C. Cobelli, Modelling methodology for physiology and medicine. Academic Press Series in Biomedical Engineering, 2001: p. xiv, 421.

92. Garny, A. and P.J. Hunter, OpenCOR: a modular and interoperable approach to computational biology. Front Physiol, 2015. 6: p. 26.

93. Hunter, P.J., E.J. Crampin, and P.M. Nielsen, Bioinformatics, multiscale modeling and the IUPS Physiome Project. Brief Bioinform, 2008. 9(4): p. 333-43.

94. Cohen, M.J., Use of models in identification and prediction of physiology in critically ill surgical patients. Br J Surg, 2012. 99(4): p. 487-93.

95. Vodovotz, Y. and T.R. Billiar, In silico modeling: methods and applications to trauma and sepsis. Crit Care Med, 2013. 41(8): p. 2008-14.

96. Chase, J., G. Shaw, X. Wong, T. Lotz, J. Lin, and C. Hann, Model-based glycaemic control in critical care $-A$ review of the state of the possible. Biomedical Signal Processing and Control, 2006. 1(1): p. 3-21.

97. Chase, J., A. LeCompte, G. Shaw, A. Blakemore, J. Wong, J. Lin, and C. Hann, A Benchmark Data Set for Model-Based Glycemic Control in Critical Care. Journal of Diabetes Science and Technology (JoDST), 2008. 24(4): p. 584-594.

98. Chase, J.G., A.J. Le Compte, J.C. Preiser, G.M. Shaw, S. Penning, and T. Desaive, Physiological modeling, tight glycemic control, and the ICU clinician: what are models and how can they affect practice? Ann Intensive Care, 2011. 1(1): p. 11.

99. Hovorka, R., L.J. Chassin, and M.E. Wilinska. Virtual type 1 diabetic treated by CSII: Model description. in WC2003. 2003. Sydney, Australia.

100. Tawhai, M.H., K.S. Burrowes, and E.A. Hoffman, Computational models of structure-function relationships in the pulmonary circulation and their validation. Exp Physiol, 2006. 91(2): p. 28593.

101. Ben-Tal, A., Simplified models for gas exchange in the human lungs. Journal of Theoretical Biology, 2006. 238(2): p. 474-495.

102. Tawhai, M.H. and C.-L. Lin, Image-based modeling of lung structure and function. Journal of Magnetic Resonance Imaging, 2010. 32(6): p. 1421-1431.

103. Tawhai, M.H. and J.H.T. Bates, Multi-scale lung modeling. Journal of Applied Physiology, 2011. 110(5): p. 1466-1472.

104. Bradley, C., A. Bowery, R. Britten, V. Budelmann, O. Camara, R. Christie, A. Cookson, A.F. Frangi, T.B. Gamage, T. Heidlauf, S. Krittian, D. Ladd, C. Little, K. Mithraratne, M. Nash, D. Nickerson, P. Nielsen, O. Nordbo, S. Omholt, A. Pashaei, D. Paterson, V. Rajagopal, A. Reeve, O. Rohrle, S. Safaei, R. Sebastian, M. Steghofer, T. Wu, T. Yu, H. Zhang, and P. Hunter, OpenCMISS: a multi-physics \& multi-scale computational infrastructure for the VPH/Physiome project. Prog Biophys Mol Biol, 2011. 107(1): p. 32-47.

105. Hunter, P., T. Chapman, P.V. Coveney, B. de Bono, V. Diaz, J. Fenner, A.F. Frangi, P. Harris, R. Hose, P. Kohl, P. Lawford, K. McCormack, M. Mendes, S. Omholt, A. Quarteroni, N. Shublaq, J. Skar, K. Stroetmann, J. Tegner, S.R. Thomas, I. Tollis, I. Tsamardinos, J.H. van Beek, and M. Viceconti, A vision and strategy for the virtual physiological human: 2012 update. Interface Focus, 2013. 3(2): p. 20130004.

106. Smith, N., S. Waters, P. Hunter, and R. Clayton, The cardiac physiome: foundations and future prospects for mathematical modelling of the heart. Prog Biophys Mol Biol, 2011. 104(1-3): p. 1.

107. Pironet, A., T. Desaive, S. Kosta, A. Lucas, S. Paeme, A. Collet, C.G. Pretty, P. Kolh, and P.C. Dauby, A multi-scale cardiovascular system model can account for the load-dependence of the end-systolic pressure-volume relationship. Biomed Eng Online, 2013. 12: p. 8.

108. Keener, J.P. and J. Sneyd, Mathematical physiology. Interdisciplinary applied mathematics v. 8. 1998, New York: Springer. viii, 766 p.

109. Wilinska, M.E., L. Chassin, and R. Hovorka, In Silico Testing_Impact on the Progress of the Closed Loop Insulin Infusion for Critically III Patients Project. Journal of Diabetes Science and Technology, 2008. 2(3): p. 417-423.

110. Pielmeier, U., S. Andreassen, B.S. Nielsen, J.G. Chase, and P. Haure, A simulation model of insulin saturation and glucose balance for glycemic control in ICU patients. Comput Methods Programs Biomed, 2010. 97(3): p. 211-22.

111. Tawhai, M.H., E.A. Hoffman, and C.-L. Lin, The lung physiome: merging imaging-based measures with predictive computational models. Wiley Interdisciplinary Reviews: Systems Biology and Medicine, 2009. 1(1): p. 61-72. 
112. Barrett, P.H., B.M. Bell, C. Cobelli, H. Golde, A. Schumitzky, P. Vicini, and D.M. Foster, SAAM II: Simulation, Analysis, and Modeling Software for tracer and pharmacokinetic studies. Metabolism, 1998. 47(4): p. 484-92.

113. Bergman, R.N., Y.Z. Ider, C.R. Bowden, and C. Cobelli, Quantitative estimation of insulin sensitivity. Am J Physiol, 1979. 236(6): p. E667-77.

114. Dalla Man, C., A. Caumo, and C. Cobelli, The oral glucose minimal model: Estimation of insulin sensitivity from a meal test. leee Transactions on Biomedical Engineering, 2002. 49(5): p. 41929.

115. Dalla Man, C., M. Camilleri, and C. Cobelli, A system model of oral glucose absorption: validation on gold standard data. IEEE Trans Biomed Eng, 2006. 53(12 Pt 1): p. 2472-8.

116. Man, C.D., M.D. Breton, and C. Cobelli, Physical activity into the meal glucose-insulin model of type 1 diabetes: in silico studies. J Diabetes Sci Technol, 2009. 3(1): p. 56-67.

117. Pillonetto, G., A. Caumo, G. Sparacino, and C. Cobelli, A new dynamic index of insulin sensitivity. IEEE Trans Biomed Eng, 2006. 53(3): p. 369-79.

118. Toffolo, G. and C. Cobelli, The hot IVGTT two-compartment minimal model: an improved version. Am J Physiol Endocrinol Metab, 2003. 284(2): p. E317-21.

119. Wilinska, M.E., L.J. Chassin, C.L. Acerini, J.M. Allen, D.B. Dunger, and R. Hovorka, Simulation environment to evaluate closed-loop insulin delivery systems in type 1 diabetes. J Diabetes Sci Technol, 2010. 4(1): p. 132-44.

120. Callegari, T., A. Caumo, and C. Cobelli, Bayesian two-compartment and classic singlecompartment minimal models: comparison on insulin modified IVGTT and effect of experiment reduction. IEEE Trans Biomed Eng, 2003. 50(12): p. 1301-9.

121. Bergman, R.N., D.T. Finegood, and M. Ader, Assessment of insulin sensitivity in vivo. Endocr Rev, 1985. 6(1): p. 45-86.

122. Ferrannini, E. and A. Mari, How to measure insulin sensitivity. J Hypertens, 1998. 16(7): p. 895906.

123. Kansal, A.R., Modeling approaches to type 2 diabetes. Diabetes Technol Ther, 2004. 6(1): p. 39-47.

124. Parker, R.S. and F.J. Doyle, 3rd, Control-relevant modeling in drug delivery. Adv Drug Deliv Rev, 2001. 48(2-3): p. 211-228.

125. Turnheim, K. and W.K. Waldhausl, Essentials of insulin pharmacokinetics. Wien Klin Wochenschr, 1988. 100(3): p. 65-72.

126. Viceconti, M., C. Cobelli, T. Haddad, A. Himes, B. Kovatchev, and M. Palmer, In silico assessment of biomedical products: The conundrum of rare but not so rare events in two case studies. Proc Inst Mech Eng H, 2017. 231(5): p. 455-466.

127. Van Herpe, T., M. Espinoza, B. Pluymers, I. Goethals, P. Wouters, G. Van den Berghe, and B. De Moor, An adaptive input-output modeling approach for predicting the glycemia of critically ill patients. Physiol Meas, 2006. 27(11): p. 1057-69.

128. Van Herpe, T., M. Espinoza, N. Haverbeke, B.D. Moor, and G.V. den Berghe, Glycemia prediction in critically ill patients using an adaptive modeling approach. J Diabetes Sci Technol, 2007. 1(3): p. 348-56.

129. Lehmann, E.D. and T. Deutsch, AIDA2: A Mk. Il automated insulin dosage advisor. J Biomed Eng, 1993. 15: p. 201-211.

130. Trajanoski, Z. and P. Wach, Neural predictive controller for insulin delivery using the subcutaneous route. IEEE Trans Biomed Eng, 1998. 45(9): p. 1122-1134.

131. Bahremand, S., H.S. Ko, R. Balouchzadeh, H. Felix Lee, S. Park, and G. Kwon, Neural networkbased model predictive control for type 1 diabetic rats on artificial pancreas system. Med Biol Eng Comput, 2018.

132. Pappada, S.M., B.D. Cameron, P.M. Rosman, R.E. Bourey, T.J. Papadimos, W. Olorunto, and M.J. Borst, Neural network-based real-time prediction of glucose in patients with insulindependent diabetes. Diabetes Technol Ther, 2011. 13(2): p. 135-41.

133. Trajanoski, Z. and P. Wach, Neural predictive controller for insulin delivery using the subcutaneous route. IEEE Trans Biomed Eng, 1998. 45(9): p. 1122-34.

134. Trajanoski, Z., W. Regittnig, and P. Wach, Simulation studies on neural predictive control of glucose using the subcutaneous route. Comput Methods Programs Biomed, 1998. 56(2): p. 133-9.

135. Van Herpe, T., B. Pluymers, M. Espinoza, G. Van den Berghe, and B. De Moor, A minimal model for glycemia control in critically ill patients. Conf Proc IEEE Eng Med Biol Soc, 2006. 1: p. 5432-5. 
136. Van Herpe, T., B. De Moor, and G. Van den Berghe, Towards closed-loop glycaemic control. Best Pract Res Clin Anaesthesiol, 2009. 23(1): p. 69-80.

137. Lin, J., N.N. Razak, C.G. Pretty, A. Le Compte, P. Docherty, J.D. Parente, G.M. Shaw, C.E. Hann, and J. Geoffrey Chase, A physiological Intensive Control Insulin-Nutrition-Glucose (ICING) model validated in critically ill patients. Comput Methods Programs Biomed, 2011. 102(2): p. 192-205.

138. Dickson, J.L., J.G. Chase, A. Lynn, and G.M. Shaw, Model-based glycaemic control: methodology and initial results from neonatal intensive care. Biomed Tech (Berl), 2016.

139. Dickson, J.L., K.W. Stewart, C.G. Pretty, M. Flechet, T. Desaive, S. Penning, B.C. Lambermont, B. Benyo, G.M. Shaw, and J.G. Chase, Generalisability of a Virtual Trials Method for Glycaemic Control in Intensive Care. IEEE Trans Biomed Eng, 2018. 65(7): p. 1543-1553.

140. Kovatchev, B.P., M. Breton, C.D. Man, and C. Cobelli, In Silico Preclinical Trials: A Proof of Concept in Closed-Loop Control of Type 1 Diabetes. J Diabetes Sci Technol, 2009. 3(1): p. 4455.

141. Van Herpe, T., D. Mesotten, P.J. Wouters, J. Herbots, E. Voets, J. Buyens, B. De Moor, and G. Van den Berghe, LOGIC-Insulin Algorithm-Guided Versus Nurse-Directed Blood Glucose Control During Critical IIIness: The LOGIC-1 single-center randomized, controlled clinical trial. Diabetes Care, 2013. 36(2): p. 189-194.

142. Dubois, J., T. Van Herpe, R.T. van Hooijdonk, R. Wouters, D. Coart, P. Wouters, A. Van Assche, G. Veraghtert, B. De Moor, J. Wauters, A. Wilmer, M.J. Schultz, G. Van den Berghe, and D. Mesotten, Software-guided versus nurse-directed blood glucose control in critically ill patients: the LOGIC-2 multicenter randomized controlled clinical trial. Crit Care, 2017. 21(1): p. 212.

143. Arleth, T., S. Andreassen, M.O. Federici, and M.M. Benedetti, A model of the endogenous glucose balance incorporating the characteristics of glucose transporters. Comput Methods Programs Biomed, 2000. 62(3): p. 219-34.

144. Pielmeier, U., S. Andreassen, B. Juliussen, J.G. Chase, B.S. Nielsen, and P. Haure, The Glucosafe system for tight glycemic control in critical care: a pilot evaluation study. J Crit Care, 2010. 25(1): p. 97-104.

145. Hovorka, R., V. Canonico, L.J. Chassin, U. Haueter, M. Massi-Benedetti, M.O. Federici, T.R. Pieber, H.C. Schaller, L. Schaupp, T. Vering, and M.E. Wilinska, Nonlinear model predictive control of glucose concentration in subjects with type 1 diabetes. Physiological Measurement, 2004. 25(4): p. 905-920.

146. Hovorka, R., J. Kremen, J. Blaha, M. Matias, K. Anderlova, L. Bosanska, T. Roubicek, M.E. Wilinska, L.J. Chassin, S. Svacina, and M. Haluzik, Blood glucose control by a model predictive control algorithm with variable sampling rate versus a routine glucose management protocol in cardiac surgery patients: a randomized controlled trial. J Clin Endocrinol Metab, 2007. 92(8): p. 2960-4.

147. Hovorka, R., Closed-loop insulin delivery: from bench to clinical practice. Nat Rev Endocrinol, 2011. 7(7): p. 385-95.

148. Wilinska, M.E., J. Blaha, L.J. Chassin, J.J. Cordingley, N.C. Dormand, M. Ellmerer, M. Haluzik, J. Plank, D. Vlasselaers, P.J. Wouters, and R. Hovorka, Evaluating glycemic control algorithms by computer simulations. Diabetes Technol Ther, 2011. 13(7): p. 713-22.

149. Le Compte, A., J.G. Chase, G. Russell, A. Lynn, C. Hann, G. Shaw, X.W. Wong, A. Blakemore, and $\mathrm{J}$. Lin, Modeling the glucose regulatory system in extreme preterm infants. Comput Methods Programs Biomed, 2010.

150. Docherty, P.D., J.G. Chase, T.F. Lotz, and T. Desaive, A graphical method for practical and informative identifiability analyses of physiological models: $A$ case study of insulin kinetics and sensitivity. Biomedical Engineering Online, 2011. 10(1): p. 1-20.

151. Docherty, P.D., J.G. Chase, and T. David, Characterisation of the iterative integral parameter identification method. Medical and Biological Engineering and Computing, 2012: p. 1-8.

152. Docherty, P.D., J.G. Chase, T.F. Lotz, C.E. Hann, G.M. Shaw, J.E. Berkeley, L. TeMorenga, J.I. Mann, and K. McAuley, Independent cohort cross-validation of the real-time DISTq estimation of insulin sensitivity. Computer Methods and Programs in Biomedicine, 2011. 102(2): p. 94-104.

153. Sah Pri, A., J.G. Chase, C.G. Pretty, G.M. Shaw, J.C. Preiser, J.L. Vincent, M. Oddo, F.S. Taccone, S. Penning, and T. Desaive, Evolution of insulin sensitivity and its variability in outof-hospital cardiac arrest (OHCA) patients treated with hypothermia. Crit Care, 2014. 18(5): p. 586. 
154. Chase, J.G., F. Suhaimi, S. Penning, J.C. Preiser, A.J. Le Compte, J. Lin, C.G. Pretty, G.M. Shaw, K.T. Moorhead, and T. Desaive, Validation of a model-based virtual trials method for tight glycemic control in intensive care. Biomed Eng Online, 2010. 9: p. 84.

155. Lonergan, T., A. LeCompte, M. Willacy, J.G. Chase, G.M. Shaw, X.W. Wong, T. Lotz, J. Lin, and C.E. Hann, A Simple Insulin-Nutrition Protocol for Tight Glycemic Control in Critical Illness: Development and Protocol Comparison. Diabetes Technol Ther, 2006. 8(2): p. 191-206.

156. Fisk, L., A. Lecompte, S. Penning, T. Desaive, G. Shaw, and G. Chase, STAR Development and Protocol Comparison. IEEE Trans Biomed Eng, 2012. 59(12): p. 3357-3364.

157. Lonergan, T., A.L. Compte, M. Willacy, J.G. Chase, G.M. Shaw, C.E. Hann, T. Lotz, J. Lin, and X.W. Wong, A pilot study of the SPRINT protocol for tight glycemic control in critically III patients. Diabetes Technol Ther, 2006. 8(4): p. 449-62.

158. Dickson, J.L., A. Lynn, G.M. Shaw, and J.G. CHASE, Safe and Effective glycaemic control in premature infants: observational clinical results from the computerised STAR-GRYPHON protocol. Archives of disease in childhood, 2018. in-press: p. 8-pages.

159. Stewart, K.W., C.G. Pretty, H. Tomlinson, F.L. Thomas, J. Homlok, S.N. Noemi, A. Illyes, G.M. Shaw, B. Benyo, and J.G. Chase, Safety, efficacy and clinical generalization of the STAR protocol: a retrospective analysis. Ann Intensive Care, 2016. 6(1): p. 24.

160. Visentin, R., C.D. Man, and C. Cobelli, One-Day Bayesian Cloning of Type 1 Diabetes Subjects: Toward a Single-Day UVA/Padova Type 1 Diabetes Simulator. IEEE Trans Biomed Eng, 2016. 63(11): p. 2416-2424.

161. Docherty, P.D., J.G. Chase, L. Morenga, T.F. Lotz, J. Berkeley, G. Shaw, K. McAuley, and J. Mann, A spectrum of dynamic insulin sensitivity test protocols. Journal of Diabetes Science and Technology, 2011. 5(6): p. 1499.

162. Lotz, T.F., J.G. Chase, K.A. McAuley, D.S. Lee, J. Lin, C.E. Hann, and J.I. Mann, Transient and steady-state euglycemic clamp validation of a model for glycemic control and insulin sensitivity testing. Diabetes Technol Ther, 2006. 8(3): p. 338-46.

163. Lotz, T.F., J.G. Chase, K.A. McAuley, G.M. Shaw, P.D. Docherty, J.E. Berkeley, S.M. Williams, C.E. Hann, and J.I. Mann, Design and clinical pilot testing of the model-based Dynamic Insulin Sensitivity and Secretion Test (DISST). Journal of Diabetes Science and Technology, 2010. 4(6): p. 1408-1423.

164. McAuley, K.A., J.E. Berkeley, P.D. Docherty, T.F. Lotz, L.A. Te Morenga, G.M. Shaw, S.M. Williams, J.G. Chase, and J.I. Mann, The dynamic insulin sensitivity and secretion test--a novel measure of insulin sensitivity. Metabolism, 2011.

165. Hann, C.E., J.G. Chase, J. Lin, T. Lotz, C.V. Doran, and G.M. Shaw, Integral-based parameter identification for long-term dynamic verification of a glucose-insulin system model. Comput Methods Programs Biomed, 2005. 77(3): p. 259-270.

166. Lin, J., D. Lee, J.G. Chase, G.M. Shaw, C.E. Hann, T. Lotz, and J. Wong, Stochastic modelling of insulin sensitivity variability in critical care. Biomedical Signal Processing and Control, 2006. 1(3): p. 229-242.

167. Lin, J., D. Lee, J.G. Chase, G.M. Shaw, A. Le Compte, T. Lotz, J. Wong, T. Lonergan, and C.E. Hann, Stochastic modelling of insulin sensitivity and adaptive glycemic control for critical care. Comput Methods Programs Biomed, 2008. 89(2): p. 141-52.

168. Hovorka, R., F. Shojaee-Moradie, P.V. Carroll, L.J. Chassin, I.J. Gowrie, N.C. Jackson, R.S. Tudor, A.M. Umpleby, and R.H. Jones, Partitioning glucose distribution/transport, disposal, and endogenous production during IVGTT. Am J Physiol Endocrinol Metab, 2002. 282(5): p. E9921007.

169. Mari, A., G. Pacini, A.R. Brazzale, and B. Ahren, Comparative evaluation of simple insulin sensitivity methods based on the oral glucose tolerance test. Diabetologia, 2005. 48(4): p. 74851.

170. Le Compte, A., J. Chase, A. Lynn, C. Hann, G. Shaw, X. Wong, and J. Lin, Blood Glucose Controller for Neonatal Intensive Care: Virtual trials development and 1st clinical trials. Journal of Diabetes Science and Technology (JoDST), 2009. 3(5): p. 1066-1081.

171. Blaha, J., B. Barteczko-Grajek, P. Berezowicz, J. Charvat, J. Chvojka, T. Grau, J. Holmgren, U. Jaschinski, P. Kopecky, J. Manak, M. Moehl, J. Paddle, M. Pasculli, J. Petersson, S. Petros, D. Radrizzani, V. Singh, and J. Starkopf, Space GlucoseControl system for blood glucose control in intensive care patients--a European multicentre observational study. BMC Anesthesiol, 2016. 16: p. 8.

172. Cobelli, C., G. Pacini, G. Toffolo, and L. Sacca, Estimation of insulin sensitivity and glucose clearance from minimal model: new insights from labeled IVGTT. Am J Physiol, 1986. 250(5 Pt 1): p. E591-8. 
173. Dalla Man, C., K.E. Yarasheski, A. Caumo, H. Robertson, G. Toffolo, K.S. Polonsky, and C. Cobelli, Insulin sensitivity by oral glucose minimal models: validation against clamp. Am J Physiol Endocrinol Metab, 2005. 289(6): p. E954-9.

174. Jamaludin, U.K., P.D. Docherty, J. Geoffrey Chase, and G.M. Shaw, Impact of Haemodialysis on Insulin Kinetics of Acute Kidney Injury Patients in Critical Care. J Med Biol Eng, 2015. 35(1): p. $125-133$.

175. Lin, J., J.D. Parente, J.G. Chase, G.M. Shaw, A.J. Blakemore, A.J. LeCompte, C. Pretty, N.N. Razak, D.S. Lee, and C.E. Hann, Development of a model-based clinical sepsis biomarker for critically ill patients. Computer Methods and Programs in Biomedicine, 2011. 102(2): p. 149155.

176. Le Compte, A.J., C.G. Pretty, J. Lin, G.M. Shaw, A. Lynn, and J.G. Chase, Impact of variation in patient response on model-based control of glycaemia in critically ill patients. Computer Methods and Programs in Biomedicine, 2011.

177. Thomas, F., C.G. Pretty, L. Fisk, G.M. Shaw, J.G. Chase, and T. Desaive, Reducing the impact of insulin sensitivity variability on glycaemic outcomes using separate stochastic models within the STAR glycaemic protocol. Biomed Eng Online, 2014. 13: p. 43.

178. Mowery, N.T., O.L. Gunter, L.A. Dossett, M.J. Dortch, J.A. Morris, Jr., A.K. May, and J.J. Diaz, Jr., Failure to achieve euglycemia despite aggressive insulin control signals abnormal physiologic response to trauma. J Crit Care, 2011. 26(3): p. 295-302.

179. Cueni-Villoz, N., A. Devigili, F. Delodder, S. Cianferoni, F. Feihl, A.O. Rossetti, P. Eggimann, J.L. Vincent, F.S. Taccone, and M. Oddo, Increased blood glucose variability during therapeutic hypothermia and outcome after cardiac arrest. Crit Care Med, 2011. 39(10): p. 2225-31.

180. Ferenci, T., B. Benyo, L. Kovacs, L. Fisk, G.M. Shaw, and J.G. Chase, Daily evolution of insulin sensitivity variability with respect to diagnosis in the critically ill. PLoS One, 2013. 8(2): p. e57119.

181. Koch, A., O.A. Gressner, E. Sanson, F. Tacke, and C. Trautwein, Serum resistin levels in critically ill patients are associated with inflammation, organ dysfunction and metabolism and may predict survival of non-septic patients. Crit Care, 2009. 13(3): p. R95.

182. Laviano, A., F. Aghilone, D. Colagiovanni, F. Fiandra, R. Giambarresi, P. Tordiglione, A. Molfino, M. Muscaritoli, G. Rosa, and F. Rossi Fanelli, Metabolic and clinical effects of the supplementation of a functional mixture of amino acids in cerebral hemorrhage. Neurocrit Care, 2011. 14(1): p. 44-9.

183. Amrein, K., M. Ellmerer, R. Hovorka, N. Kachel, D. Parcz, S. Korsatko, K. Smolle, S. Perl, G. Bock, W. Doll, G. Kohler, T.R. Pieber, and J. Plank, Hospital glucose control: safe and reliable glycemic control using enhanced model predictive control algorithm in medical intensive care unit patients. Diabetes Technol Ther, 2010. 12(5): p. 405-12.

184. Amrein, K., M. Ellmerer, R. Hovorka, N. Kachel, H. Fries, D. von Lewinski, K. Smolle, T.R. Pieber, and J. Plank, Efficacy and safety of glucose control with Space GlucoseControl in the medical intensive care unit--an open clinical investigation. Diabetes Technol Ther, 2012. 14(8): p. 690-5.

185. Blaha, J., P. Kopecky, M. Matias, R. Hovorka, J. Kunstyr, T. Kotulak, M. Lips, D. Rubes, M. Stritesky, J. Lindner, M. Semrad, and M. Haluzik, Comparison of three protocols for tight glycemic control in cardiac surgery patients. Diabetes Care, 2009. 32(5): p. 757-61.

186. Pachler, C., J. Plank, H. Weinhandl, L.J. Chassin, M.E. Wilinska, R. Kulnik, P. Kaufmann, K.H. Smolle, E. Pilger, T.R. Pieber, M. Ellmerer, and R. Hovorka, Tight glycaemic control by an automated algorithm with time-variant sampling in medical ICU patients. Intensive Care Med, 2008. 34(7): p. 1224-30.

187. Bally, L., H. Thabit, S. Hartnell, E. Andereggen, Y. Ruan, M.E. Wilinska, M.L. Evans, M.M. Wertli, A.P. Coll, C. Stettler, and R. Hovorka, Closed-Loop Insulin Delivery for Glycemic Control in Noncritical Care. N Engl J Med, 2018. 379(6): p. 547-556.

188. Evans, A., G.M. Shaw, A. Le Compte, C.S. Tan, L. Ward, J. Steel, C.G. Pretty, L. Pfeifer, S. Penning, and F. Suhaimi, Pilot proof of concept clinical trials of Stochastic Targeted (STAR) glycemic control. Annals of Intensive Care, 2011. 1(1): p. 38.

189. Evans, A., A. Le Compte, C.S. Tan, L. Ward, J. Steel, C.G. Pretty, S. Penning, F. Suhaimi, G.M. Shaw, and T. Desaive, Stochastic Targeted (STAR) Glycemic Control: Design, Safety, and Performance. Journal of Diabetes Science and Technology, 2012. 6(1): p. 102-115.

190. Le Compte, A.J., D.S. Lee, J.G. Chase, J. Lin, A. Lynn, and G.M. Shaw, Blood glucose prediction using stochastic modeling in neonatal intensive care. IEEE Trans Biomed Eng, 2010. 57(3): p. 509-18. 
191. Uyttendaele, V., J.L. Knopp, K.W. Stewart, T. Desaive, B. Benyó, N. Szabo-Nemedi, A. Illyés, G.M. Shaw, and J.G. Chase, A 3D insulin sensitivity prediction model enables more patientspecific prediction and model-based glycaemic control. Biomedical Signal Processing and Control, 2018. 46: p. 192-200.

192. Le Compte, A.J., A.M. Lynn, J. Lin, C.G. Pretty, G.M. Shaw, and J.G. Chase, Pilot study of a model-based approach to blood glucose control in very-low-birthweight neonates. BMC Pediatr, 2012. 12: p. 117.

193. Alsweiler, J.M., J.E. Harding, and F.H. Bloomfield, Tight glycemic control with insulin in hyperglycemic preterm babies: a randomized controlled trial. Pediatrics, 2012. 129(4): p. 63947.

194. Beardsall, K., S. Vanhaesebrouck, A.L. Ogilvy-Stuart, C. Vanhole, C.R. Palmer, M. van Weissenbruch, P. Midgley, M. Thompson, M. Thio, L. Cornette, I. Ossuetta, I. Iglesias, C. Theyskens, M. de Jong, J.S. Ahluwalia, F. de Zegher, and D.B. Dunger, Early insulin therapy in very-low-birth-weight infants. N Engl J Med, 2008. 359(18): p. 1873-84.

195. Target Investigators, f.t.A.C.T.G., Energy-Dense versus Routine Enteral Nutrition in the Critically III. N Engl J Med, 2018. 379(19): p. 1823-1834.

196. Cahill, N.E., R. Dhaliwal, A.G. Day, X. Jiang, and D.K. Heyland, Nutrition therapy in the critical care setting: what is "best achievable" practice? An international multicenter observational study. Crit Care Med, 2010. 38(2): p. 395-401.

197. Villet, S., R.L. Chiolero, M.D. Bollmann, J.P. Revelly, R.N.M. Cayeux, J. Delarue, and M.M. Berger, Negative impact of hypocaloric feeding and energy balance on clinical outcome in ICU patients. Clin Nutr, 2005. 24(4): p. 502-9.

198. Wischmeyer, P.E., The evolution of nutrition in critical care: how much, how soon? Crit Care, 2013. 17 Suppl 1: p. S7.

199. Stewart, K.W., J.G. Chase, C.G. Pretty, and G.M. Shaw, Nutrition delivery of a model-based ICU glycaemic control system. Ann Intensive Care, 2018. 8(1): p. 4.

200. Stewart, K.W., J.G. Chase, C.G. Pretty, and G.M. Shaw, Nutrition delivery, workload and performance in a model-based ICU glycaemic control system. Comput Methods Programs Biomed, 2018. 166: p. 9-18.

201. Davidson, P.C., R.D. Steed, and B.W. Bode, Glucommander: a computer-directed intravenous insulin system shown to be safe, simple, and effective in 120,618 h of operation. Diabetes Care, 2005. 28(10): p. 2418-23.

202. Juneja, R., A.A. Golas, J. Carroll, D. Nelson, V.J. Abad, C.P. Roudebush, and S.J. Flanders, Safety and effectiveness of a computerized subcutaneous insulin program to treat inpatient hyperglycemia. J Diabetes Sci Technol, 2008. 2(3): p. 384-91.

203. Marvin, M.R., S.E. Inzucchi, and B.J. Besterman, Computerization of the Yale insulin infusion protocol and potential insights into causes of hypoglycemia with intravenous insulin. Diabetes Technol Ther, 2013. 15(3): p. 246-52.

204. Alsweiler, J., K. Williamson, F. Bloomfield, G. Chase, and J. Harding, Computer-determined dosage of insulin in the management of neonatal hyperglycaemia (HINT2): protocol of a randomised controlled trial. BMJ Open, 2017. 7(3): p. e012982.

205. Suhaimi, F., A. Le Compte, J.C. Preiser, G.M. Shaw, P. Massion, R. Radermecker, C. Pretty, J. Lin, T. Desaive, and J.G. Chase, What Makes Tight Glycemic Control (TGC) Tight? The impact of variability and nutrition in 2 clinical studies. Journal of Diabetes Science and Technology, 2010. 4(2): p. 284-298.

206. Hewson, M., V. Nawadra, J. Oliver, C. Odgers, J. Plummer, and K. Simmer, Insulin infusions in the neonatal unit: delivery variation due to adsorption. J Paediatr Child Health, 2000. 36(3): p. 216-20.

207. Jakobsson, T., R. Shulman, H. Gill, and K. Taylor, The impact of insulin adsorption onto the infusion sets in the adult intensive care unit. J Diabetes Sci Technol, 2009. 3(1): p. 213-4.

208. Bequette, B.W., A critical assessment of algorithms and challenges in the development of a closed-loop artificial pancreas. Diabetes Technol Ther, 2005. 7(1): p. 28-47.

209. Dassau, E., C.C. Palerm, H. Zisser, B.A. Buckingham, L. Jovanovic, and F.J. Doyle, In silico evaluation platform for artificial pancreatic beta-cell development--a dynamic simulator for closed-loop control with hardware-in-the-loop. Diabetes Technol Ther, 2009. 11(3): p. 187-94.

210. Signal, M., C.G. Pretty, J.G. Chase, A. Le Compte, and G.M. Shaw, Continuous glucose monitors and the burden of tight glycemic control in critical care: can they cure the time cost? J Diabetes Sci Technol, 2010. 4(3): p. 625-35. 